\title{
Uptake of Cd(II) Using Natural Zeolite: Batch and Continuous Fixed-Bed Studies
}

\author{
Luna M. Marashdeha and Ahmad M. Al-Haj-Ali*b \\ a Department of Chemical Engineering, University of Jordan, Amman 11942, Jordan \\ ${ }^{* b}$ Department of Petroleum and Chemical Engineering, Sultan Qaboos University, P.O. Box 33, Al-Khod 123, \\ Muscat, Sultanate of Oman
}

Received 31 December 2007; accepted 7 October 2008
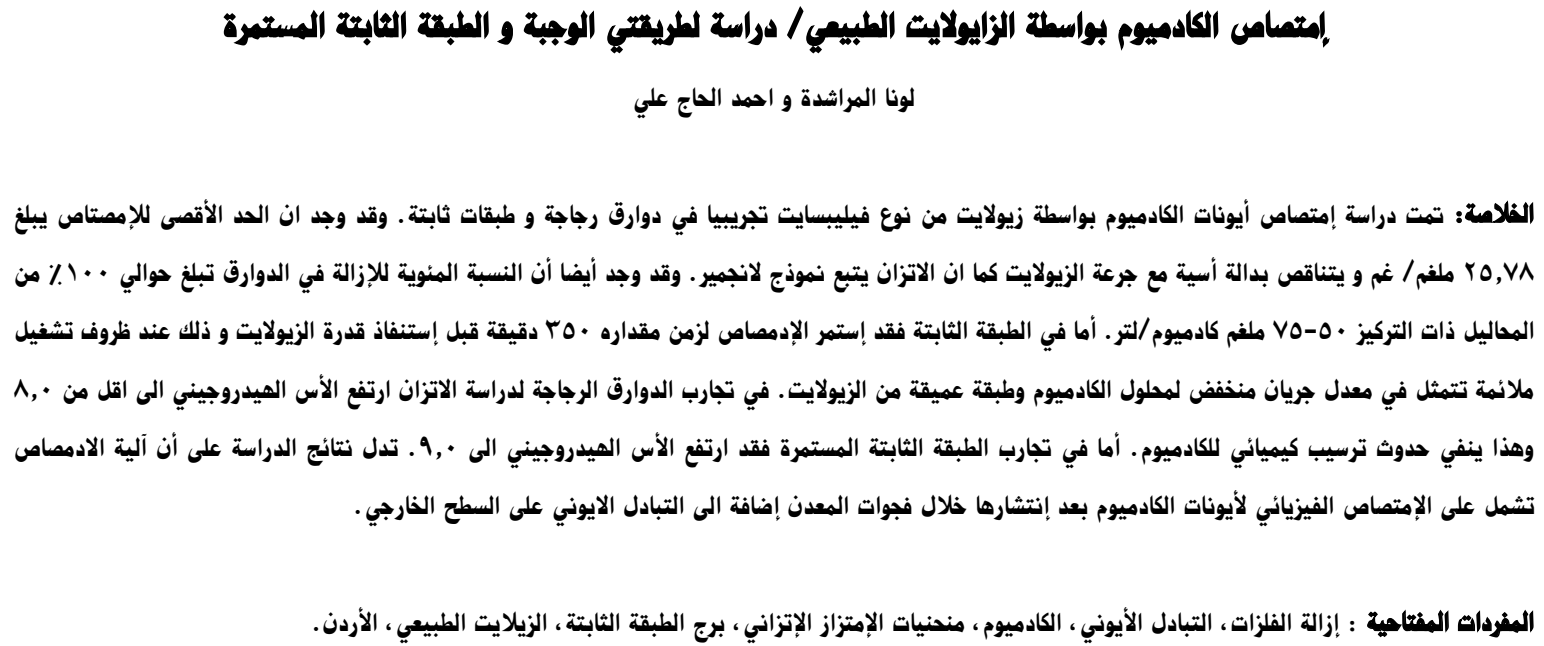

Abstract: Uptake of Cd(II) ions by natural phillipsite tuff was investigated both in shake-flask and fixed-bed columns. Equilibrium uptake, $\mathrm{q}_{\mathrm{e}}$, was found to best fit Langmuir adsorption isotherm with a maximum value of $25.78 \mathrm{mg} / \mathrm{g}$. Percent removal of Cd ions was close to $100 \%$ from initial metal ion concentrations in the range $50-75 \mathrm{mg} / \mathrm{L}$ at $5.0 \mathrm{~g}$ zeolite/L. Also, qe was found to vary exponentially with zeolite dose. Break points as high as 350 minutes were obtained from bed treatment at favorable conditions of a low solution flow rate and high bed depth. In batch experiments, equilibrium $\mathrm{pH}$ increased to $<8.0$ excluding chemical precipitation as part of the removal while in fixed-beds the final $\mathrm{pH}$ exceeded 9.0. It is suggested that a sieve action of zeolite porous structure plays a role as an uptake mechanism in addition to the ion exchange.

Keywords: Metal uptake, Ion exchange, Cadmium, Adsorption isotherms, Fixed-bed column, Natural Zeolite, Jordan

\section{Notation}

b Langmuir isotherm parameter related to adsorption energy $(\mathrm{L} / \mathrm{mg})$

$\mathrm{C}_{\mathrm{o}} \quad$ Initial Cd ion concentration (mg/L)

$\mathrm{C}_{\mathrm{e}} \quad$ Equilibrium Cd ion concentration (mg/L)

D Zeolite Dose in equilibrium experiments (g / L solution).

IUPAC International Union of Pure and Applied Chemistry

$\mathrm{K} \quad$ Equilibrium constant of $\mathrm{Cd}$ hydrolysis reaction

$\mathrm{K}_{\mathrm{F}} \quad$ Freundlich isotherm parameter related to adsorption capacity (L/g)

$\mathrm{n} \quad$ Freundlich isotherm parameter related to adsorption intensity (dimensionless)

$\mathrm{q}_{\mathrm{e}} \quad$ Equilibrium uptake (mg Cd/g zeolite)

$\mathrm{q}_{\mathrm{m}} \quad$ Experimental parameter indicating maximum uptake (mg/g)

$\mathrm{Q}_{\mathrm{L}} \quad$ Langmuir isotherm parameter related to adsorption capacity (mg/g)

$r \quad$ Dimensionless separation factor to describe the type of adsorption

$\mathrm{S} \quad$ Experimental coefficient $(\mathrm{L} / \mathrm{g})$

$\mathrm{Z} \quad$ symbol representing active sites on the zeolite surface.

*Corresponding author’s e-mail: abuyaghi@ju.edu.jo 


\section{Introduction}

Heavy metal ions are major pollutants in the wastewaters of many industrial activities. Cadmium is introduced into the aquatic environment by discharge of liquid effluents with relatively low metal concentration from smelting, metal plating, cadmium-nickel batteries, phosphate fertilizer, mining, paints, metal alloys and other chemical and engineering industries (Alloway, 1995; Stumm and Morgan, 1996). Such metal ions are soluble in water and could penetrate through soil layers thus polluting soil, public water supplies and accumulating in agricultural crops. Cd is the most toxic element readily taken up by plants (Dabrowski et al. 2004). Therefore, the removal of $\mathrm{Cd}$ and other metal ions from waste effluents before their discharge is a health and environmental priority required by international and local standards. The harmful effects of cadmium on human health are well documented including a number of acute and chronic disorders such as renal damage, anemia and hypertension (Friberg et al. 1974).

The discharge limits from industrial effluents vary according to fate or application of wastewater. For example, the maximum allowable concentration of $\mathrm{Cd}$ in the Jordanian Wastewater (both industrial and treated domestic sewage) Standards is $0.01 \mathrm{mg} / \mathrm{L}$ for reuse in irrigation and discharge to streams and lakes; $0.02 \mathrm{mg} / \mathrm{L}$ for underground water recharge and $0.07 \mathrm{mg} / \mathrm{L}$ for discharge to the sea. Drinking water guideline value for $\mathrm{Cd}$ recommended by World Health Organization (WHO) is $0.005 \mathrm{mg} / \mathrm{L}$ (WHO, 2004), which is adopted by the Jordanian standard for drinking water. Two engineering techniques for heavy metal removal are usually applied, namely chemical precipitation and ion exchange. These methods suffer from disadvantages such as non-selectivity, high cost and waste disposal problems.

Natural zeolites are crystalline microporous aluminosilicates with well-defined structures that consist of a framework formed by tetrahedra of $\mathrm{SiO}_{4}$ and $\mathrm{AlO}_{4}$ connected through oxygen atoms. The frame-work contains channels and cavities with molecular dimensions from 0.3 to $1 \mathrm{~nm}$ occupied by alkaline and alkaline earth metal cations as well as water molecules. These cations possess the ability to move freely and can be exchanged by more selective cations from aqueous solutions (Sand and Mumpton, 1978).

In several parts of the world, natural zeolites have been used as ion exchangers for the removal of ammonium ions from municipal wastewater (Hedstrom, 2001); cesium and strontium ions from radioactive wastewater and heavy metals from industrial wastewater (Ouki et al. 1994). Fixed beds of zeolite may be used as packing materials in subsurface barriers to control ground water pollution (Cincotti et al. 2006). These applications are stimulated by the non-toxic nature of zeolites as well as their availability in the many countries. Application of natural zeolites for the removal of heavy metals such as Cd(II), $\mathrm{Pb}(\mathrm{II}), \mathrm{Ni}(\mathrm{II})$, etc. has been reported in several studies considering both in equilibrium batch experiments (Berber-Mendoza, et al. 2006; Alvarez-Ayuso, 2003; Lee and Moon, 2001) as well as dynamic fixed-bed column experiments (Inglezakis and Grigoropoulou, 2004; AlHaj-Ali and Al-Hunaidi, 2004) or both (Vaca-Mier, et al. 2001). Results of the above studies indicated that natural zeolites possess good ion exchange properties and thus can be used to substitute or assist ion exchange systems employing commercial synthetic resins in heavy metal removal from wastewater. This recommendation is based on relatively high removal efficiency as well as low cost of the mineral.

In the northeastern part of Jordan, large deposits of natural zeolite produced by alteration of basaltic glass are present. Currently this mineral is being mined and made commercially available for agricultural applications where it is used as a soil conditioner. Environmental applications of this mineral, particularly as an adsorbent / ion exchange) has been the subject of investigation for more than 15 years. Published studies on this mineral have shown that it is of a promising potential in heavy metal removal from wastewater (Dwairi, 1992; Al-Haj-Ali and El-Bishtawi, 1997, Rashdan, 2002). This zeolite has become a commercial commodity in the local market available at low prices. The fact that natural zeolite can be regenerated after heavy metal removal makes it even more attractive as an ion exchanger. According to Rashdan (2002), reactivation of zeolite loaded with $\mathrm{Pb}, \mathrm{Cd}, \mathrm{Ni}, \mathrm{Cu}$ and $\mathrm{Zn}$ ions with $\mathrm{CaCl}_{2}$, $\mathrm{KCl}$ or $\mathrm{NaNO}_{3}$ was successful up to $80-100 \%$ of the pre-adsorbed amounts of the indicated metals depending on the metal as well as the type and concentration of eluant solution.

The main objectives of this study are to evaluate the ability of natural Jordanian zeolite for Cd ions removal under certain conditions both in batch and continuous fixed-bed contact modes.

\section{Experimental}

\subsection{Materials}

The zeolite used in this work was phillipsite-rich tuff mined from the Aritain mountain area in the northeastern part of Jordan and supplied by the Natural Resources Authority of Jordan. The zeolite was crushed using a Jaw crusher and sieved into three size cuts, namely, 355-500, 500-710 and 710-850 $\mu \mathrm{m}$. Particles were washed with tap water until the dust and fines are removed. The mineral was immersed in 25g. $\mathrm{dm}^{-3}$ solution of $\mathrm{NaCl}$ (analytical reagent, Analar Co.) in distilled, deionized water at room temperature for $24 \mathrm{~h}$. The solution was replaced by a fresh one and the mineral continued to be immersed for another $24 \mathrm{~h}$. The sodium homo-ionic zeolite was then filtered, washed gently with distilled, deionized water and ovendried at $35{ }^{\circ} \mathrm{C}$. The chemical composition of raw zeolite (as received) was obtained by x-ray fluorescence (XRF) analysis and is given in Table 1 , which also presents related physical properties of the zeolite. The Langmuir and BET surface areas, total pore volume and average pore 
Table 1. Physical and chemical properties of zeolite tuff

\author{
For un-sieved zeolite \\ True Density \\ Bulk Density \\ Color
}

For size cut $\mathbf{3 5 5}-\mathbf{5 0 0} \mathbf{~} \mathbf{m}$
Langmuir Surface Area
BET Surface area
Total Pore Volume
Avg. Pore Diameter

For size cut $\mathbf{7 1 0 - 8 5 0 ~ \mu m}$

Langmuir Surface Area

BET Surface are a

Total Pore Volume

Avg. Pore Diameter

$$
\begin{aligned}
& 2.380 \mathrm{~g} / \mathrm{cm}^{3} \\
& 1.035 \mathrm{~g} / \mathrm{cm}^{3} \\
& \text { Yellowish Brown }
\end{aligned}
$$

$$
\begin{aligned}
& 124 \mathrm{~m}^{2} / \mathrm{g} \\
& 92 \mathrm{~m}^{2} / \mathrm{g} \\
& 4.02 \times 10^{-2} \mathrm{~cm}^{3} / \mathrm{g}
\end{aligned}
$$$$
1.75 \AA
$$$$
\begin{aligned}
& 120 \mathrm{~m}^{2} / \mathrm{g} \\
& 90 \mathrm{~m}^{2} / \mathrm{g} \\
& 3.90 \times 10^{-2} \mathrm{~cm}^{3} / \mathrm{g} \\
& 1.75 \AA \quad(\AA=0.1 \mathrm{ì} \mathrm{m})
\end{aligned}
$$

$\begin{array}{lc}\begin{array}{l}\text { Zeolite } \\ \text { Composition* }\end{array} & \begin{array}{r}\text { Weight } \\ \text { Percent }\end{array} \\ \mathrm{SiO}_{2} & 34.20 \\ \mathrm{Al}_{2} \mathrm{O}_{3} & 10.57 \\ \mathrm{FeO} & 7.02 \\ \mathrm{CaO} & 11.35 \\ \mathrm{MgO} & 7.28 \\ \mathrm{~K}_{2} \mathrm{O} & 2.00 \\ \mathrm{Na}_{2} \mathrm{O} & 1.65 \\ \mathrm{TiO}_{2} & 1.23 \\ \text { Other } & 0.33 \\ & \\ * \text { Un-sieved } & \\ \end{array}$

diameter were determined for two zeolite sieve cuts (355500 and 500-710 $\mu \mathrm{m}$ ) using a Quantachrome Autosorb automated gas sorption system. Data are calculated and reported using Autosorb 1 program for nitrogen at 77K.

Cadmium nitrate was used as sources for Cd ions. Stock solutions of $1000 \mathrm{mg} / \mathrm{L}$ were prepared by dissolving the exact weight of $\mathrm{Cd}\left(\mathrm{NO}_{3}\right)_{2} \cdot 4 \mathrm{H}_{2} \mathrm{O}$ in distilled-deionized water and used to provide the desired $\mathrm{Cd}$ ion concentration by proper dilution. Glassware was cleaned by detergent and double rinsed thoroughly by tap water and distilled-deionized water.

\subsection{Equipment, Procedures and Sample Analysis}

\subsubsection{Batch Experiments}

Equilibrium uptake was determined by shake-flask batch experiments. A volume $150 \mathrm{~mL}$ of solution containing 50 or $75 \mathrm{mg} / \mathrm{L}$ was placed in a $250 \mathrm{~mL}$ Erlenmeyer flask. The initial $\mathrm{pH}$ was adjusted to a specified initial value (4.0 or 5.5) while the final $\mathrm{pH}$ was not controlled. An accurately-weighed zeolite mass (in the range 0.12-1.2 g) was added to the solution thus making slurry concentration in the range $1.0-8.0 \mathrm{~g} / \mathrm{L}$.

A series of such flasks was then agitated at a constant speed in a laboratory shaker at room temperature (20$22^{\circ} \mathrm{C}$ ). After 120 hours of contact to ensure that equilibrium is attained, the zeolite particles were separated by filtration. A sample of the solid-free solution was analyzed for Cd remaining concentration using a using flame atomic absorption spectrophotometer (Pye-Unicam Model). Before sample analysis, the AAS was calibrated using certified standard cadmium solutions. Meanwhile, the final $\mathrm{pH}$ of the solution was measured using Mettler Toledo $\mathrm{pH}$ meter calibrated with three standard buffer solutions of $\mathrm{pH}$ 4.01, 7.00 and 9.21.

In another group of shake-flask experiments, blank runs involving zeolite in distilled-deionized water (no cadmium present) were conducted to investigate the effect of adsorbent on solution $\mathrm{pH}$. In these experiments, the same solution volume, slurry concentration and initial $\mathrm{pH}$ were maintained and the same procedure above was followed. A third group of shake-flask experiments were conducted to investigate the effect of $\mathrm{pH}$ on chemical precipitation of cadmium in the absence of zeolite adsorbent. Solutions at initial concentrations of 24, 48, 70 and $91 \mathrm{mg} \mathrm{Cd} / \mathrm{L}$ were shaked in $250-\mathrm{mL}$ flasks at a specified $\mathrm{pH}$ value ranging from 4.0 to 10.0 then samples of precipitate-free solution were analyzed for remaining Cd concentration using AAS technique as indicated above.

\subsubsection{Continuous Experiments}

These experiments were conducted using a laboratory scale glass column, $1.5 \mathrm{~cm}$ inside diameter and $90 \mathrm{~cm}$ height. The column is gently packed with different masses of zeolite which provide different bed depths. The feed solution is pumped from a glass storage tank to an overhead constant-level tank made of plexi-glass and fed to the column through a glass flow meter capable of reading in the range $10-80 \mathrm{~cm}^{3} \cdot \mathrm{min}^{-1}$. Flow control is achieved by valves fitted at the top and at the bottom of column. A filter is located at both ends of the column and flexible connections permit column to be charged, sampled, emptied and washed. Samples at zero time (from solutions before contact with zeolite) as well samples from effluent solutions are withdrawn at predetermined times in the range of 3 to $450 \mathrm{~min}$ ). The concentrations of $\mathrm{Cd}$ in these samples were measured using AAS as discussed above. Experimental column variables and their tested ranges are given in Table 2.

\section{Results and Discussion}

\subsection{Equilibrium Uptake}

Equilibrium uptake ( $\mathrm{q}_{\mathrm{e}}$, mg Cd/g zeolite) was calculated from the following mass balance equation:

$$
q_{e}=(C o-C e) / D
$$




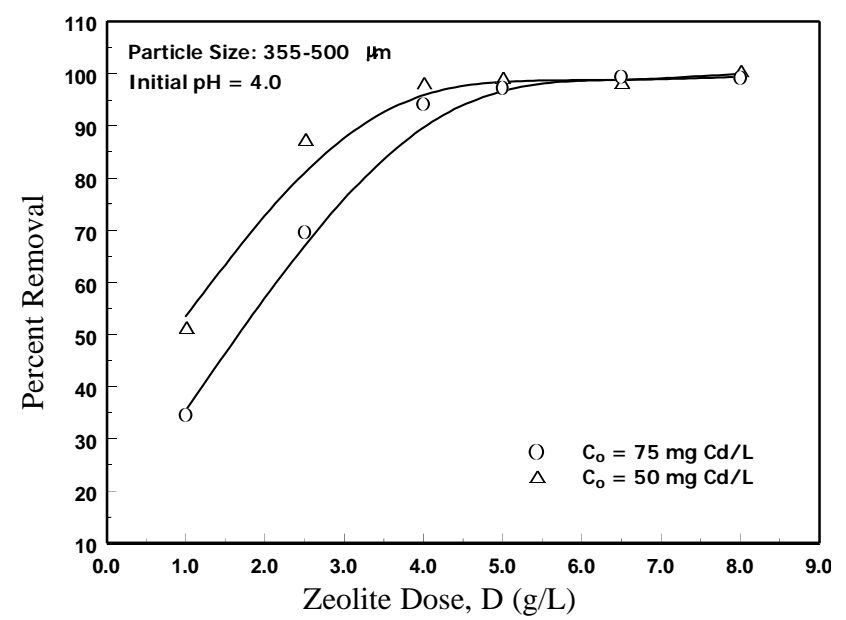

(1a)

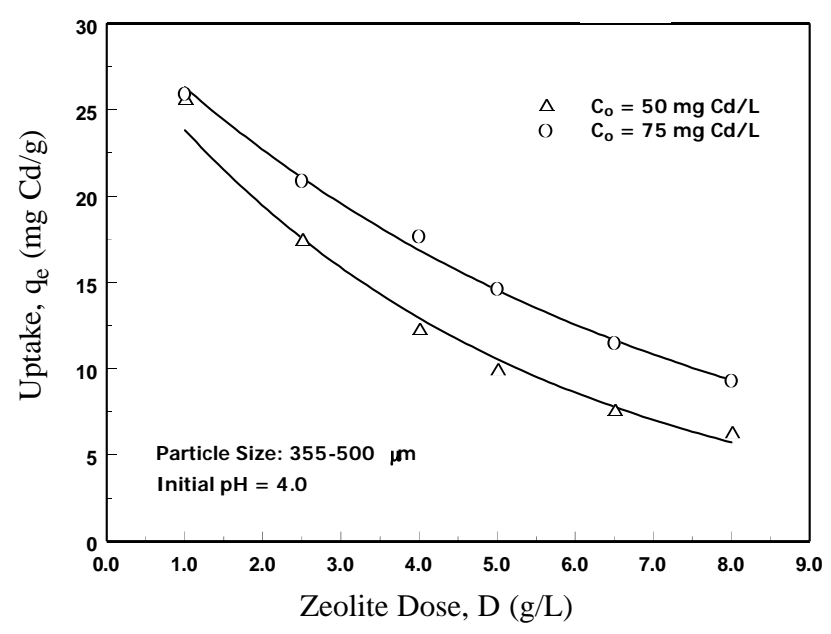

(1b)

Figure 1. Effect of zeolite dose on (a) Percent removal (b) Equilibrium uptake

Experiments were carried out to determine the equilibrium uptake using different zeolite doses. The results obtained are plotted as percent cadmium ion removal versus D (Fig. 1a) and as $\mathrm{q}_{\mathrm{e}}$ versus D (Fig. 1b) for two initial Cd II ion concentrations $\left(\mathrm{C}_{\mathrm{o}}=50\right.$ and $\left.75 \mathrm{mg} / \mathrm{L}\right)$. Figure 1 (a) shows that almost $100 \%$ removal was possible using a minimum $5 \mathrm{~g} / \mathrm{L}$ of zeolite at both initial concentrations. At lower $\mathrm{D}$ values, removal percent was higher for the lower $\mathrm{C}_{\mathrm{o}}$ value as expected with a difference of $\sim 17 \%$ at $1 \mathrm{~g}$ zeolite/L.

As a general trend and for all cases, it is clear that as the amount of zeolite per unit volume of solution is increased, metal uptake is significantly reduced. This observation is explained by the competition between metal ions for active (ion exchange) sites on the zeolite surface. Higher $\mathrm{C}_{0}$ resulted in higher uptake per unit mass of zeolite $\left(\mathrm{q}_{\mathrm{e}}\right)$. Using non-linear regression technique, the data plotted in Fig. 1 (b) are found to best fit an exponential decay function in the form:

$$
q_{e}=q_{m} \cdot \exp (-S . D)
$$

Parameter $\mathrm{q}_{\mathrm{m}}(\mathrm{mg} / \mathrm{g})$ is the upper limit of this decay function at minimum $\mathrm{D}$ indicating maximum uptake. The correlation coefficients for the two curves shown are 0.996 and 0.989 indicating good fit. Parameter $S$ indicates how sharp is the change of metal uptake, $\mathrm{q}_{\mathrm{e}}$, with zeolite dose, $\mathrm{D}$, that is, the slope of this relationship. The quantity qm increases as $\mathrm{C}_{0}$ increases.

\subsection{Equilibrium pH}

In Fig. 2, the equilibrium solution $\mathrm{pH}$ is plotted as a function of zeolite dose for the two initial concentration values considered. The solution $\mathrm{pH}$ has increased sharply from 4.0 for zeolite-free solution to 6.48 after addition of $0.8 \mathrm{~g}$ zeolite/L. Final $\mathrm{pH}$ continued to increase with increasing zeolite dose up to 7.72 at $\mathrm{D}=8.0 \mathrm{~g}$ zeolite $/ \mathrm{L}$ for $\mathrm{C}_{\mathrm{o}}=50 \mathrm{mg} / \mathrm{L}$. Similarly, pH increased between 6.37 and
7.34 when $\mathrm{D}$ increased from 0.8 to $8.0 \mathrm{~g}$ zeolite/L for $\mathrm{C}_{\mathrm{o}}$ $=75 \mathrm{mg} / \mathrm{L}$. At any zeolite dose, equilibrium $\mathrm{pH}$ is found to be slightly lower for the higher initial metal ion concentration. At $\mathrm{D}=8.0 \mathrm{~g}$ zeolite/ $\mathrm{L}$, the final $\mathrm{pH}$ is 7.34 for $\mathrm{C}_{\mathrm{o}}$ $=75 \mathrm{mg} / \mathrm{L}$ while it is 7.72 for $50 \mathrm{mg} / \mathrm{L}$. Similar observations have been reported by many authors investigating zeolite / metal systems. Al-Haj-Ali and El-Bishtawi (1997) investigated $\mathrm{Pb}(\mathrm{II})$ and $\mathrm{Ni}(\mathrm{II})$ sorption by a fine sieve cut from the same zeolite mineral and found that solution $\mathrm{pH}$ increased from an initial value of 4.0 to an equilibrium value of 5.7-7.9 for $\mathrm{Pb}(\mathrm{II})$ and to 6.9-7.3 for $\mathrm{Ni}(\mathrm{II})$ ions. Moderate changes in $\mathrm{pH}$ were also reported by Genc-Fuhrman, et al. (2007) for Cd(II) adsorption on natural clinoptilolite, alumina and sand. The solution $\mathrm{pH}$ increased from 6.5 initially to 7.7, 7.4 and 7.2, respectively at a zeolite dose of $20 \mathrm{~g} / \mathrm{L}$ at equilibrium. The results obtained in this study are also in agreement with those of by Alvarez-Ayuso et al. (2003) who investigated Cd ions uptake by clinoptilolite natural zeolite from Greece. They have found that starting with initial $\mathrm{Cd}$ ion concentrations of 50,60 and $75 \mathrm{mg} / \mathrm{L}$, the equilibrum $\mathrm{pH}$ values were 7.1 , 7.0 and 6.9 , respectively.

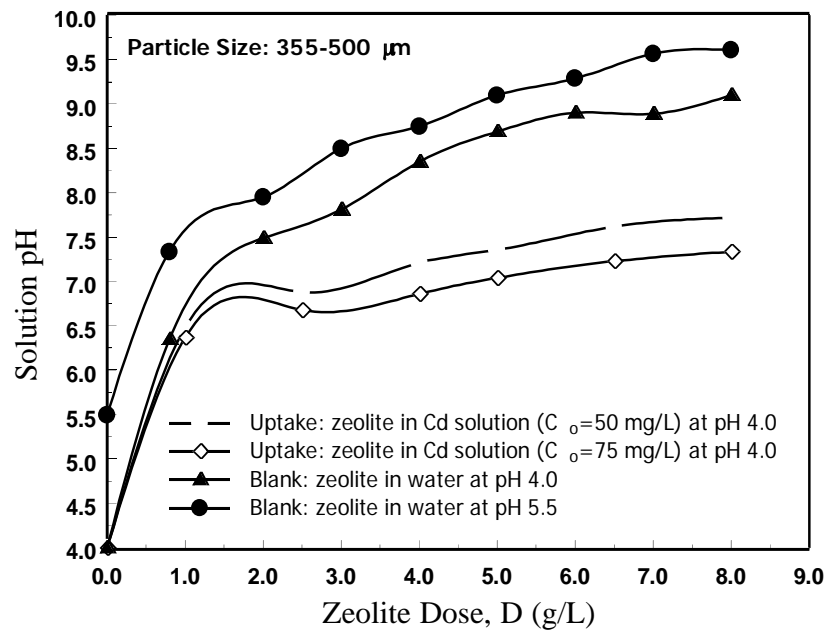

Figure 2. Equilibrium $\mathrm{pH}$ for cadmium uptake and blank systems 
Table 2. Break time in zeolite beds at different experimental conditions

\begin{tabular}{|c|c|c|c|c|c|c|c|c|}
\hline No. & $\begin{array}{l}\text { Flow Rate, } \\
\text { F (mL/min) }\end{array}$ & $\begin{array}{l}\text { Bed } \\
\text { Depth, } \\
\text { H (cm)* }\end{array}$ & $\begin{array}{l}\text { Initial } \\
\text { Cd(II) } \\
\text { Conc., } \\
\text { (mg/L) }\end{array}$ & $\mathrm{C}_{\mathrm{o}}$ & $\begin{array}{l}\text { Particle } \\
\text { Size Cut, } \\
(\mu \mathrm{m})\end{array}$ & $\begin{array}{l}\text { Initial } \\
\text { Solution } \\
\text { pH }\end{array}$ & $\begin{array}{l}\text { Break } \\
\text { Time, } \\
\text { t }_{\mathbf{B}} \text { (min) }\end{array}$ & $\begin{array}{l}\mathbf{H} / \mathbf{F} \\
(\mathrm{min} \\
\left./ \mathrm{cm}^{2}\right)\end{array}$ \\
\hline 1 & 22 & 14.4 & 50 & & $355-500$ & 4.0 & 95 & 0.65 \\
\hline 2 & 15 & 14.4 & 50 & & $355-500$ & 4.0 & 215 & 0.96 \\
\hline 3 & 10 & 14.4 & 50 & & $355-500$ & 4.0 & 350 & 1.44 \\
\hline 4 & 10 & 9.6 & 50 & & $355-500$ & 4.0 & 190 & 0.96 \\
\hline 5 & 10 & 4.8 & 50 & & $355-500$ & 4.0 & 75 & 0.48 \\
\hline 6 & 15 & 14.4 & 100 & & $355-500$ & 5.5 & 105 & 0.96 \\
\hline 7 & 15 & 14.4 & 75 & & $355-500$ & 5.5 & 130 & 0.96 \\
\hline 8 & 15 & 14.4 & 50 & & $355-500$ & 5.5 & 230 & 0.96 \\
\hline 9 & 15 & 14.4 & 75 & & $355-500$ & 4.0 & 130 & 0.96 \\
\hline 10 & 15 & 14.4 & 75 & & $710-850$ & 4.0 & 110 & 0.96 \\
\hline 11 & 15 & 14.4 & 50 & & $500-710$ & 4.0 & 130 & 0.96 \\
\hline 12 & 15 & 14.4 & 50 & & $500-710$ & 5.5 & 140 & 0.96 \\
\hline
\end{tabular}

*Corresponding to 10,20 and $30 \mathrm{~g}$ of zeolite mass

Table 3. Specification of cadmium due to aqueous dissolution and hydrolysis reactions

\begin{tabular}{|c|c|c|c|c|c|}
\hline$\#$ & Reactions in Water & pK & $\begin{array}{c}\text { Aqueous } \\
\text { Species of } \\
\text { Interest }\end{array}$ & pH Range & References \\
\hline 1 & $\begin{array}{l}\mathrm{Cd}\left(\mathrm{NO}_{3}\right)_{2} \cdot 4 \mathrm{H}_{2} \mathrm{O} \rightarrow \mathrm{Cd}^{2+}+ \\
2 \mathrm{NO}_{3}^{-}+4 \mathrm{H}_{2} \mathrm{O}\end{array}$ & $\mathrm{NA}$ & $\mathrm{Cd}^{2+}$ & $\begin{array}{l}\text { Dominant at } \leq \\
8.0\end{array}$ & \multirow{4}{*}{$\begin{array}{l}\text { Berber- } \\
\text { Mendoza, et } \\
\text { al. (2006), } \\
\text { Stumm and } \\
\text { Morgan } \\
\text { (1996), } \\
\text { Srivastava, et } \\
\text { al. (2004), } \\
\text { Burgess } \\
\text { (1988) }\end{array}$} \\
\hline 2 & $\begin{array}{l}\mathrm{Cd}^{2+}+\mathrm{H}_{2} \mathrm{O} \Leftrightarrow \mathrm{Cd}(\mathrm{OH})^{+}+ \\
\mathrm{H}^{+}\end{array}$ & 7.9 & $\mathrm{Cd}(\mathrm{OH})^{+}$ & $\begin{array}{l}\text { Formed above } \\
8.0 \text {, Dominant at } \\
9.0\end{array}$ & \\
\hline 3 & $\begin{array}{l}\mathrm{Cd}^{2+}+2 \mathrm{H}_{2} \mathrm{O} \Leftrightarrow \mathrm{Cd}(\mathrm{OH})_{2} \\
(\mathrm{aq})^{+}+2 \mathrm{H}^{+}\end{array}$ & 19.1 & $\mathrm{Cd}(\mathrm{OH})_{2}$ & $\begin{array}{l}\text { Starts to form } \\
\text { above } \\
\text { dominant at } 10.6 \text {, }\end{array}$ & \\
\hline 4 & $\begin{array}{l}\mathrm{Cd}^{2+}+3 \mathrm{H}_{2} \mathrm{O} \Leftrightarrow \mathrm{Cd}(\mathrm{OH})_{3}+ \\
3 \mathrm{H}^{+}\end{array}$ & 30.3 & $\mathrm{Cd}(\mathrm{OH})_{3}^{-}$ & $\begin{array}{l}\text { Dominant above } \\
13\end{array}$ & \\
\hline
\end{tabular}

The final solution $\mathrm{pH}$ is the resultant of two effects; firstly the initial $\mathrm{pH}$ of the cadmium nitrate solution, and secondly the addition of zeolite particles to that solution. It is known that the $\mathrm{pH}$ of $\mathrm{Cd}\left(\mathrm{NO}_{3}\right) 2.4 \mathrm{H}_{2} \mathrm{O}$ solution (and other similar metal salts) is below 7.0 , the $\mathrm{pH}$ of pure water, since this is a weak salt obtained from a strong acid $\left(\mathrm{HNO}_{3}\right)$ and a weak base $\left[\mathrm{Cd}(\mathrm{OH})_{2}\right]$. As an example, the $\mathrm{pH}$ of a solution whose $\mathrm{C}_{\mathrm{o}}=70 \mathrm{mg} \mathrm{Cd} / \mathrm{L}$ is 5.7 ; the lower the $\mathrm{Cd}$ initial concentration, the higher is the solution $\mathrm{pH}$.

The effect of the second parameter, that is, addition of zeolite was experimentally investigated for two different initial $\mathrm{pH}$ values (4.0 and 5.5) using a zeolite particle size cut of 355-500 $\mu \mathrm{m}$ in distilled-deionized water (blank runs). The results are shown also in Fig. 2 along with equilibrium $\mathrm{pH}$ from uptake experiments. In general, the final $\mathrm{pH}$ of zeolite-extract is always higher than that of the water. It is seen that as the zeolite dose added to water increased from 0.8 to $8.0 \mathrm{~g} / \mathrm{L}$, the final $\mathrm{pH}$ significantly increased from 4.0 to 8.9 and from 5.5 to 9.6. This is due to release of alkaline species from the active sites on the zeolite surfaces in contact with water which has been demonstrated by similar studies involving natural zeolite (Vaca-Mier, et al. 2001, Alvarez-Ayuso, et al. 2003; Camilo, et al. 2005; Kocaoba, et al. 2007).

Raw natural zeolite possesses a significant content of alkaline metals (Ca, Mg, $\mathrm{K}$ and $\mathrm{Na}$ ). Sodium is the major species contributing to $\mathrm{pH}$ rise in the case of the particular natural zeolite used in the study since it has been added to the mineral preparing it as $\mathrm{Na}^{+}$ion exchanger. Calcium carbonate, present as an impurity in the zeolite tuff is expected to take part in the $\mathrm{pH}$ rising process. It is noteworthy that the higher the initial $\mathrm{pH}$ of water, the higher the final equilibrium $\mathrm{pH}$ of zeolite-water slurry; the difference narrows down at high $\mathrm{D}$. The decrease in solution $\mathrm{pH}$ due to the removal of $\mathrm{Cd}$ ions from solution by zeolite will counter the rise in $\mathrm{pH}$ due to zeolite dissolution thus maintaining $\mathrm{pH}$ level below 8.0 compared to blank experimets resulting in high $\mathrm{pH}$ levels (9.1- 9.6).

The fact that equilibrium $\mathrm{pH}$ increases during metal uptake ( $\mathrm{Pb}, \mathrm{Ni}, \mathrm{Cd}, \mathrm{Cu}$, etc.) raises a concern about possible chemical precipitation of metal ions as hydroxide thus 
masking true uptake or ion exchange. Kocaoba, et al. (2007) declared that most of the heavy metal ions tend to precipitate at $\mathrm{pH}>6$ and thus making it difficult to quantify true adsorption. Cadmium may be an exception from this general statement as indicated by cadmium specification data in Table 3 which is compiled by referring to different aqueous chemistry and metal removal publications. The main relevant conclusion from this Table is that chemical precipitation does nor occur at $\mathbf{p H}<\mathbf{8 . 0}$. Other published studies give more insight about the possibility of precipitation during the course of sorption. Deliyanni and Matiz (2002) conducted their experiments on $\mathrm{Cd}$ sorption by synthetic akaganeite $[\beta-\mathrm{FeO}(\mathrm{OH})]$ up to $\mathrm{pH}$ 9.5 from a solution of $10 \mathrm{mg} \mathrm{Cd} / \mathrm{L}$ considering that cadmium removal at this $\mathrm{pH}$ is due only to sorption. They based their conclusion on the thermodynamic aqueous speciation of $\mathrm{Cd}$ which indicates that chemical precipitation (as hydroxide) is not taking place below $\mathrm{pH}$ 9.5. Srivastava, et al. (2004) in their study on Cd adsorption on kaolinite considered $\mathrm{Cd}^{2+}$ as the only species dominant up to $\mathrm{pH} 10$. Using solutions containing $15 \mathrm{mg} \mathrm{Cd} / \mathrm{L}$, they excluded chemical precipitation as a Cd removal mechanism in the studied range. However, Rangel-Mendez and Streat (2002) reported that $\mathrm{Cd}$ exists predominantly as $\mathrm{Cd}\left(\mathrm{H}_{2} \mathrm{O}\right)_{6}{ }^{2+}$ ions and precipitates as $\mathrm{Cd}(\mathrm{OH})_{2}$ just below pH 8.

The results of shake-flask experiments conducted to determine the $\mathrm{pH}$ at which $\mathrm{Cd}$ precipitates from solutions at 24, 48, 70 and $91 \mathrm{mg} / \mathrm{L}$ in absence of zeolite are shown in Fig. 3 as percent cadmium reduction against $\mathrm{pH}$. This Figure indicates that precipitation of $\mathrm{Cd}$ ions as $\mathrm{Cd}(\mathrm{OH})_{2}$ is rather slight (less than 10\%) below pH 8.6 for both initial concentration of 24 and $48 \mathrm{mg} / \mathrm{L}$. For the two higher initial concentrations of 70 and $91 \mathrm{mg} / \mathrm{L}$, precipitation is significant only beyond $\mathrm{pH}$ 8.3. These results are in agreement with the above-mentioned studies (Deliyanni and Matiz, 2002; Srivastava, et al. 2004; Berber-Mendoza, et al. 2006). Since the maximum $\mathrm{pH}$ reached in batch uptake experiments in this study is less than 8.0 (Fig. 2), therefore chemical precipitation of cadmium at $\mathrm{pH}<8.0$ is ruled out and Cd removal is confirmd as a totally sorption process. The uptake mechanism is discussed further in Section 3.5.

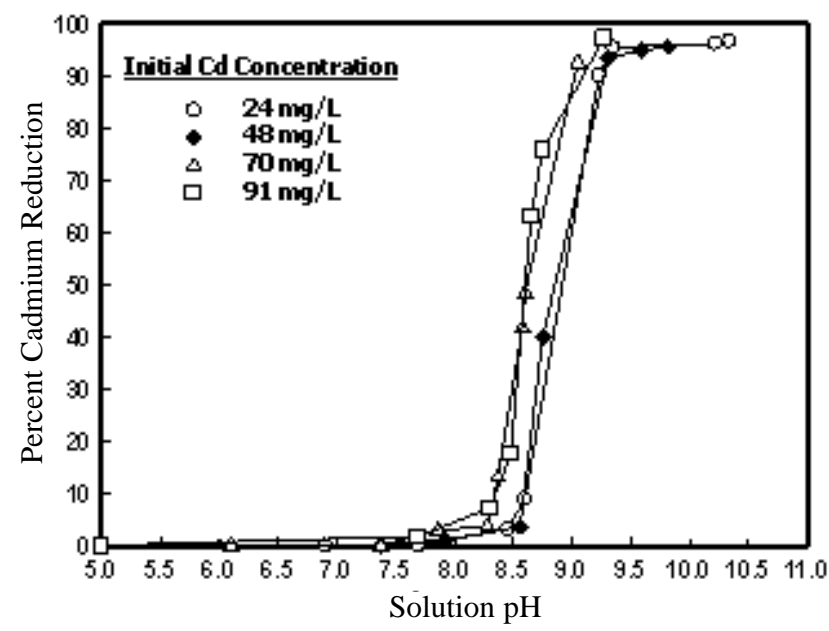

Figure 3. Percent cadmium reduction versus solution pH

\subsection{Modeling Uptake with Adsorption Isotherms}

The adsorptive capacity of a solid is concluded from equilibrium sets of data that need to be fitted to mathematical models to facilitate design of adsorption systems and broaden their application. Equilibrium uptake data were fitted to popular models of adsorption isotherms, namely; Langmuir, Freundlich and Sips models. Langmuir isotherm has the following non-linear form:

$$
q_{e}=Q_{L} b \cdot C_{e} /\left(1+b \cdot C_{e}\right)
$$

Based on parameter " $b$ ", the dimensionless separation factor, $r$, is defined as follows:

$$
r=1 /\left(1+b \cdot C_{O}\right)
$$

This factor is used to decide whether the adsorption process is favorable $(0<\mathrm{r}<1)$ or not. In the Cd(II) / phillipsite tuff system investigated, " $r$ " has the values of 0.02 and 0.03 for initial concentrations of 75 and $50 \mathrm{mg} / \mathrm{L}$, respectively, indicates a very favorite adsorption process. Freundlich isotherm has the following form:

$$
q_{e}=K_{F} \cdot C_{e}^{1 / n}
$$

The predictions of the two models are shown in Fig. 4 compared to experimental data. Regression analysis has shown that Langmuir isotherm represents the data better than Freundlich isotherm (correlation coefficients, $\mathrm{R}^{2}$, are 0.995 and 0.977 , respectively. This is an indication of mono-layer coverage of metal ions binded to specific sites rather than accumulation of ions on particle surfaces. Langmuir and Freundlich isotherms parameters obtained in this study by fitting experimental equilibrium data to these models are given in Table 4 compared to those reported in the literature for cadmium uptake by other adsorbents and ion exchangers. The Langmuir parameter, QL, represents the maximum sorption capacity which is $25.78 \mathrm{mg} \mathrm{Cd} / \mathrm{g}$ for the system being studied. This is a relatively high sorption capacity compared with the performance of other sorbents from the same nature, ie. soils and minerals.

\subsection{Breakthrough Curves}

The effects of solution flow-rate, bed depth, initial concentration of $\mathrm{Cd}$ ions in the feed, zeolite particle size and initial solution $\mathrm{pH}$ on the sorption behavior of $\mathrm{Cd}(\mathrm{II})$ ions are presented and discussed. The breakthrough time $\left(t_{B}\right)$ is taken as an indicator of zeolite bed efficiency and defined as the time required to reach the breakpoint assumed to be at $5 \%$ breakthrough (that is, the time at which $\mathrm{C} / \mathrm{C}_{\mathrm{o}}=$ 0.05). The higher the break time, the higher is the metal uptake and the more efficient is the bed. The $t_{B}$ values obtained from various breakthrough curves describing Cd(II) uptake by zeolite bed are given in Table 2 along with the respective column parameters. 
Table 4. Cd(II) adsorption parameters of Jordanian zeolite compared to other zeolites and mineral adsorbents

\section{Reference}

Garcia-Sanchez et al. Sepiolite, Spain (1999)

Singh et al. (2001)

\section{Phosphatic}

Florida, US

Alvarez-Ayuso et al. Clinoptilolite, Greece (2003)

Berber-Mendoza et al. Clinoptilolite, Mexico (2006)

Cincotti et al. (2006)

Sprynskyy

et al. (2006) (2007)

Genc-Fuhrman et. al. Sand, Denmark (2007)

Genc-Fuhrman et al. Alumina, Denmark (2007)

Genc-Fuhrman et al. Fly ash, Denmark (2007)

This work

Phillipsite tuff, Jordan

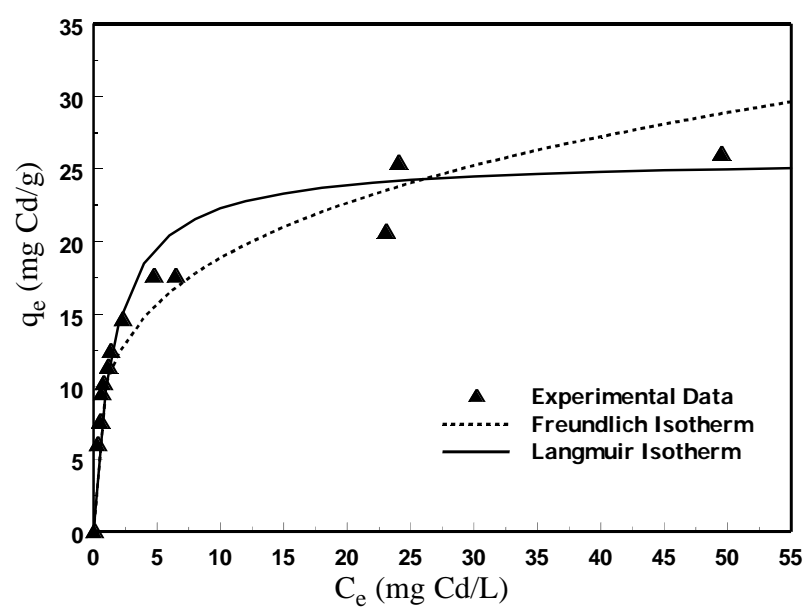

Figure 4. Modeling experimental data with a adsorption isotherms

\subsubsection{Effect of Solution Flow Rate}

Breakthrough curves obtained using three solution flow-rates keeping other parameters constant (zeolite mass $=30 \mathrm{~g}$ equivalent to $14.4 \mathrm{~cm}$ of bed depth) are shown in Fig. 5. Break times of 350 and 215 min obtained at the low $\mathrm{F}$ values of 10 and $15 \mathrm{~mL} / \mathrm{min}$ are considered high and denotes an efficient bed. However, the bed performance would be lower at higher solution flow rates. This is inferred from the significantly shorter break time at $22 \mathrm{~mL} / \mathrm{min}$.

\begin{tabular}{|c|c|c|c|}
\hline \multirow{2}{*}{$\begin{array}{l}\text { Langmuir } \\
\text { Parameters } \\
Q_{L} \text { (mg/g) }\end{array}$} & \multirow{2}{*}{ b (L/mg) } & \multicolumn{2}{|c|}{$\begin{array}{l}\text { Freundlich } \\
\text { Parameters }\end{array}$} \\
\hline & & $K_{F}(L / g)$ & $\mathbf{n}$ \\
\hline 8.26 & 1.67 & 6.17 & 3.80 \\
\hline 24.5 & 0.111 & --- & --- \\
\hline 4.60 & 0.162 & --- & --- \\
\hline 29.11 & 0.022 & 20.57 & 2.22 \\
\hline 10.40 & 1.08 & --- & --- \\
\hline 4.88 & 0.078 & 0.636 & 2.20 \\
\hline --- & --- & 0.21 & 1.07 \\
\hline --- & --- & 0.42 & 3.57 \\
\hline --- & --- & 6.35 & 0.86 \\
\hline--- & --- & 5.01 & 0.64 \\
\hline 25.78 & 0.636 & 10.29 & 3.78 \\
\hline
\end{tabular}

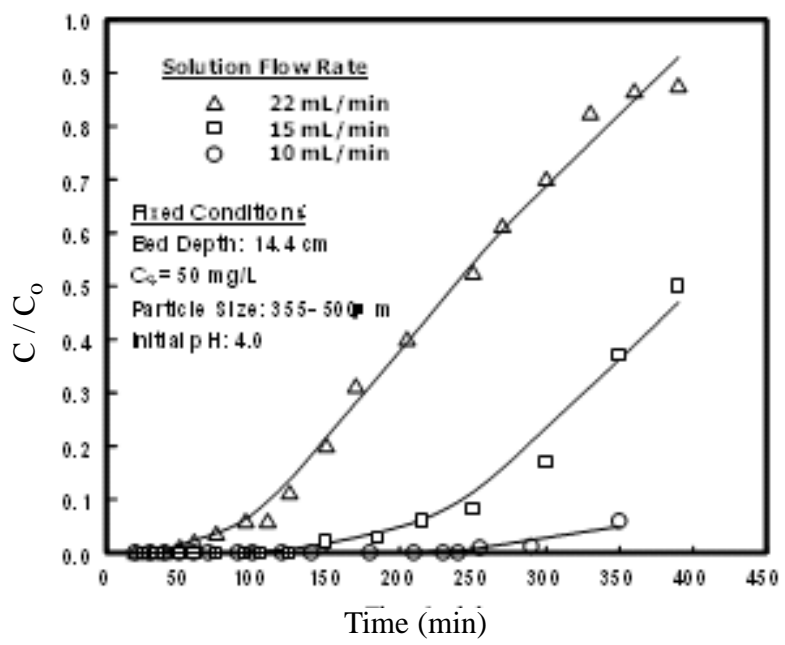

Figure 5. Breakthrough curves at variable solution flow rate

\subsubsection{Effect of Bed Depth}

In Fig. 6, the bed depth $(\mathrm{H})$ was varied keeping all other parameters constant. As expected, the highest value of $t_{B}$ was obtained using the highest bed depth $(14.4 \mathrm{~cm})$ corresponding to the highest zeolite mass available. Decreasing $\mathrm{H}$ while keeping $\mathrm{F}$ constant at $10 \mathrm{~mL} / \mathrm{min}$ ) resulted in shorter break time. It is concluded that at the conditions tested, a bed depth less than $9.6 \mathrm{~cm}$ (zeolite mass less than 20 g) will not give a satisfactory performance.

The effect of bed depth, $\mathrm{H}$, and solution flow rate, $\mathrm{F}$, 


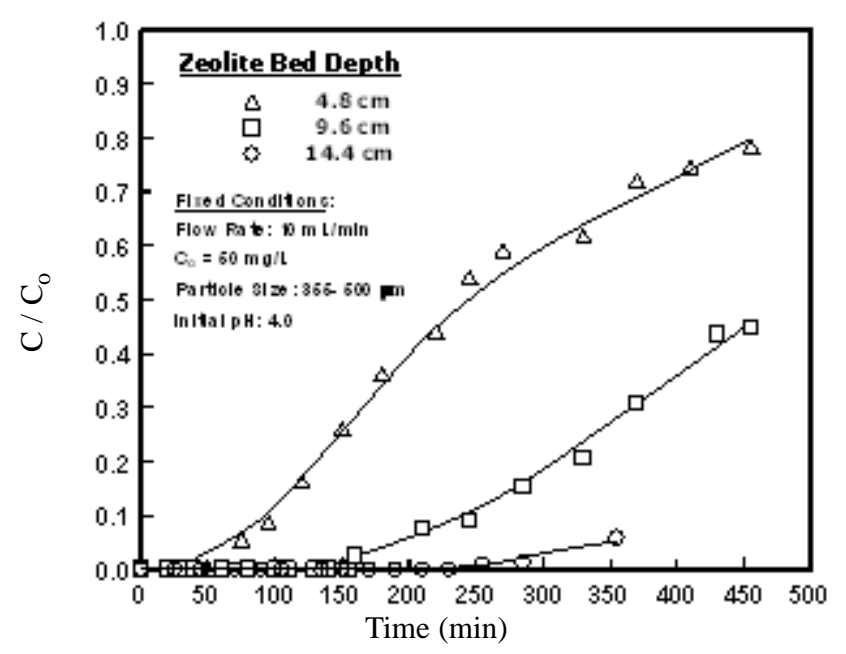

Figure 6. Breakthrough curves at variable bed depth

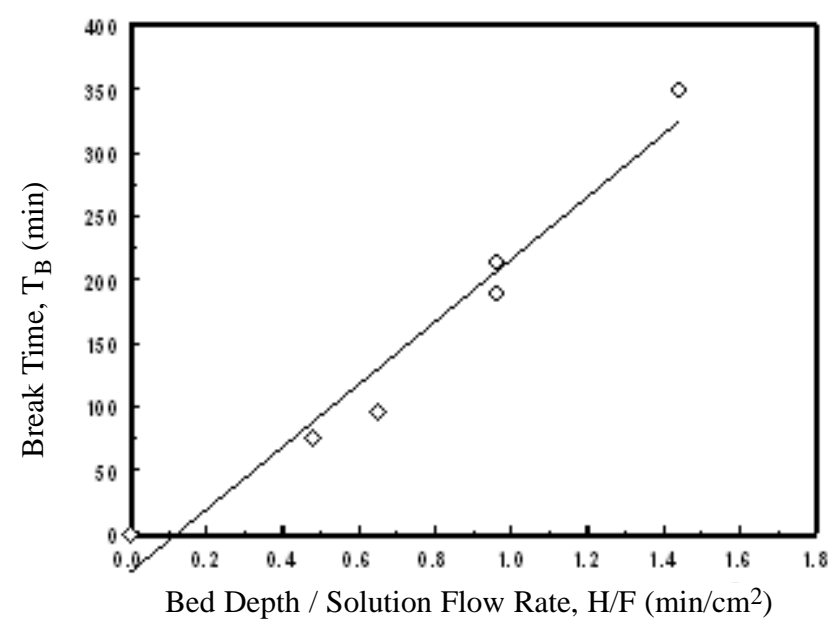

Figure 7. Effect of bed-depth to solution flow-rate ratio, $\mathrm{H} / \mathrm{F}$

can be combined in one parameter, the $\mathrm{H} / \mathrm{F}$ ratio which has the units of $\mathrm{min} / \mathrm{cm}^{2}$. The break time, $\mathrm{tB}$ is plotted versus $\mathrm{H} / \mathrm{F}$ for the data given in Table (2) obtained at constant $\mathrm{C}_{\mathrm{o}}(50 \mathrm{mg} / \mathrm{L})$, constant initial $\mathrm{pH}$ of solution (4.0) and using one size cut of particles $(355-500 \mu \mathrm{m})$. The point of original $(0,0)$ is also included in the data. Linear regression supported a straight line (Fig. 7) with 0.957 correlation coefficient, 246.7 as the slope and -30.4 as the intercept.

The basic idea behind the H/F ratio is the complementing roles of sorbent bed depth and flow rate of feed solution. Furthermore, it is an interaction of two effects, namely, the availability of active surface sites from the sorbent side and the adequacy of residence time from the solution side. Both factors are crucial for a successful sorption process which usually involves mass transfer of ions from the aqueous phase to solid surface and the subsequent binding to that surface. Using high bed depth, which provides easily accessible ion exchange sites, compensates for lack of sufficient residence time of ions in contact with the bed. To simplify the idea, it can be said that for a given removal efficiency, using high bed depth with high flow rate is the same as using a low bed depth with a low flow rate.

\subsubsection{Effect of Initial Cd ion Concentration}

Figure 8 shows the effect of $\mathrm{Cd}(\mathrm{II})$ ion concentration in feed solution, $\mathrm{C}_{0}$, on break time is shown in maintaining constant $\mathrm{F}=15 \mathrm{~mL} / \mathrm{min}$ and $\mathrm{H}=14.4 \mathrm{~cm}$. The slopes of breakthrough curves decreased as $\mathrm{C}_{0}$ decreased indicating better sorption behavior at lower $\mathrm{C}_{0}$, where break time reached 230 min compared to 150 and $105 \mathrm{~min}$ at the higher $\mathrm{C}_{\mathrm{o}}$ values of 75 and $100 \mathrm{mg} / \mathrm{L}$, respectively. This observation is in agreement with the findings of Takac and Calik (1998) for ion exchange.

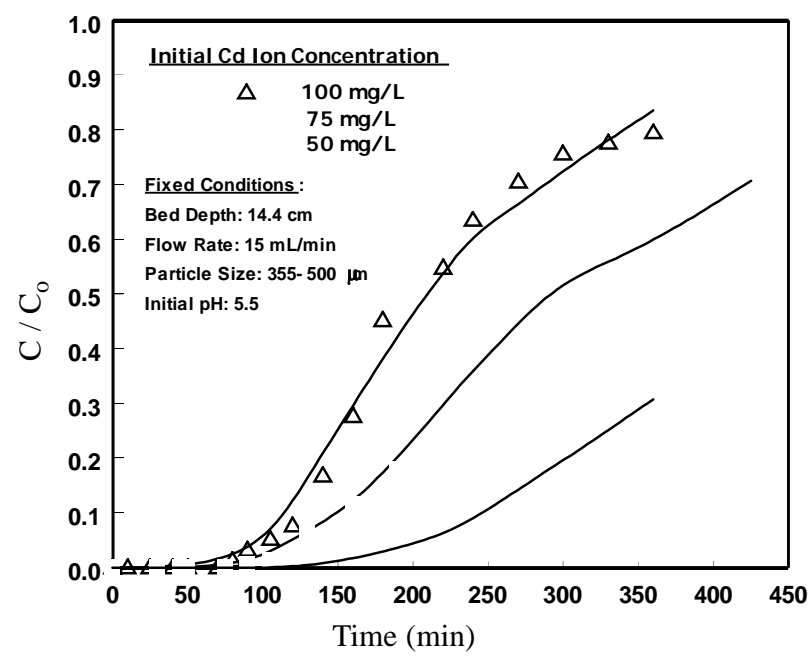

Figure 8. Breakthrough curves at variable initial Cd ion concentration

\subsubsection{Effect of Zeolite Particle Size}

The effect of zeolite particle size on breakthrough curves is shown in Fig. 9. The effect is not large where break time decreased only by $15 \%$ when coarse particles (710-850 $\mu \mathrm{m}$ ) are used compared to the case of the finer particles $(355-500 \mu \mathrm{m})$. A look at Table (1) reveals that these two size cuts have similar physical properties in terms of specific surface area (91- $\left.92 \mathrm{~m}^{2} / \mathrm{g}\right)$ and average pore diameter $(1.75 \AA)$. Therefore, it is not surprising that the two zeolite fractions exhibit comparable sorption performances.

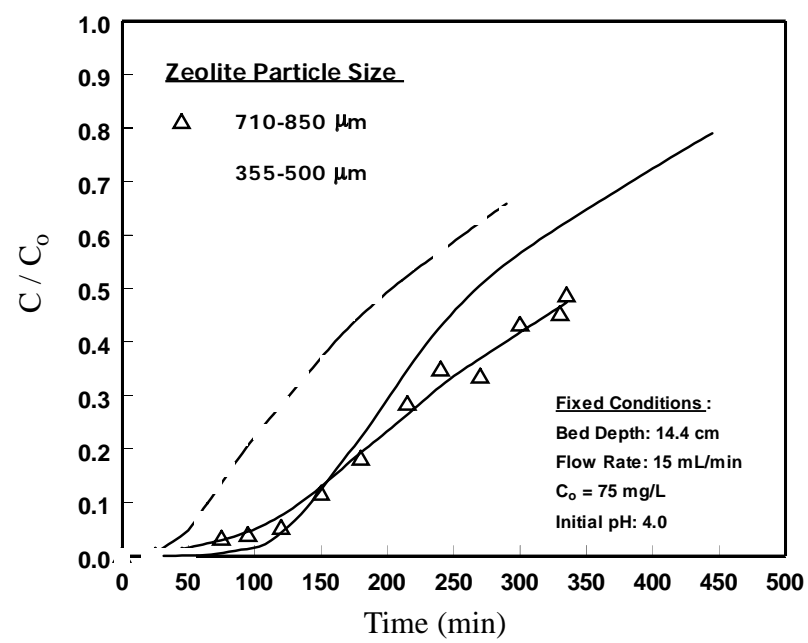

Figure 9. Breakthrough curves at different zeolite particle sizes 


\subsubsection{Effect of Initial Solution $\mathrm{pH}$ and Change in $\mathrm{pH}$}

Figure 10 involves two breakthrough curves obtained using solutions at two initial $\mathrm{pH}$ values keeping other parameters constant. Little effect is observed (about 10\% more) in break time as $\mathrm{pH}$ increased from 4.0 to 5.5 . This is a well-known observation in metal uptake studies which is explained by the fact that the concentration of hydrogen ions $\left(\mathrm{H}^{+}\right)$, which competes with $\mathrm{Cd}$ ions for attachment on zeolite sites, decreases with $\mathrm{pH}$ increase thus enhancing $\mathrm{Cd}$ ions removal. Hence, the bed reaches break point earlier at $\mathrm{pH} 5.5$ than in the case of $\mathrm{pH} 4.0$.

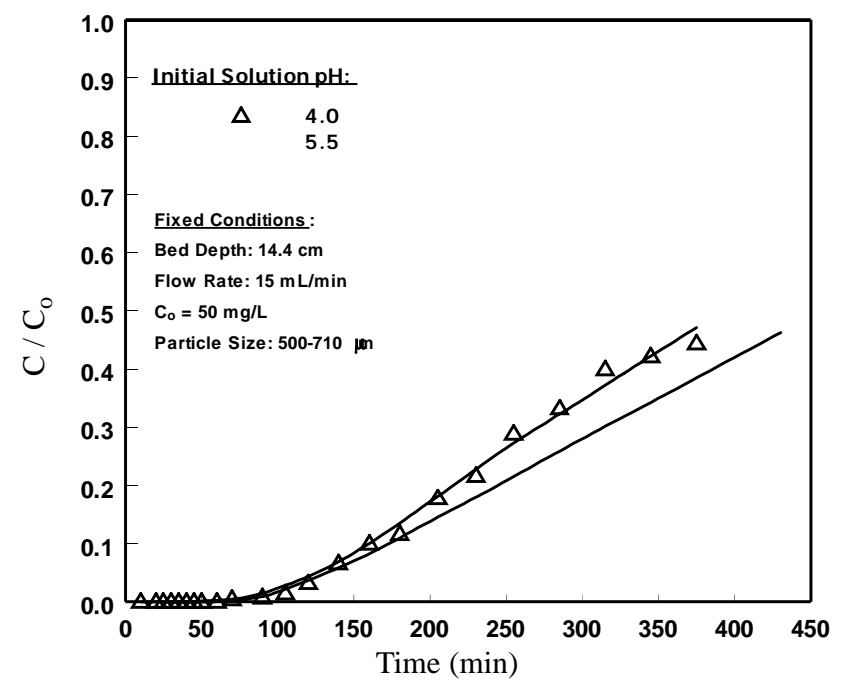

Figure 10. Breakthrough curves at different initial solution $\mathbf{p H}$ values

The changes of solution $\mathrm{pH}$ during cadmium ion uptake in a typical experiment are shown in Fig. 11. Starting with feed solutions initially adjusted to $\mathrm{pH} 4.0$ or 5.5; the solution $\mathrm{pH}$ during sorption has risen sharply in the first 15 minutes to 8.4- 9.0 then declined slowly and leveled off at

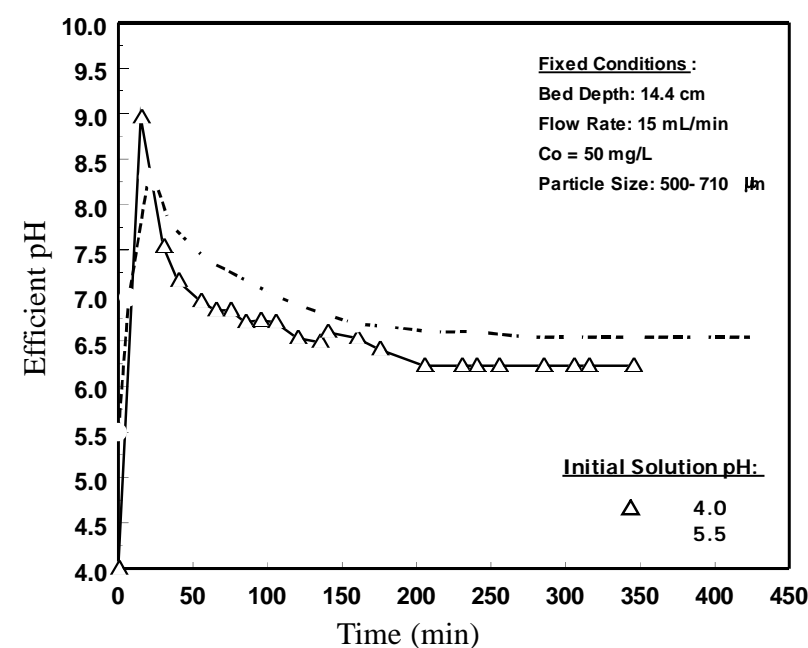

Figure 11. Changes in effluent solution $\mathrm{pH}$ with time in zeolite fixed-bed

6.2- 6.5. Based on the discussion in Section 3.2, chemical precipitation in the form of $\mathrm{Cd}(\mathrm{OH})_{2}$ will occur at when $\mathrm{pH}$ 8.0-8.5 is exceeded thus masking the sorption process.
The reason for this sharp rise in $\mathrm{pH}$ during the initial sorption stage is explained in the light of the kinetics of ion exchange occurring in the bed. Both the sodium release and cadmium uptake occur initially at high rates in the upper fresh zone of the bed where the driving forces for these processes are high. At later stages down the bed, the driving forces of these processes will decrease and solution $\mathrm{pH}$ is levelled off. It is recommended, therefore, that $\mathrm{pH}$ inside zeolite beds should also be maintained below 8.0 to avoid deposition of precipitate on the surface of particles. Such deposition will make it difficult and impractical to regenerate the zeolite bed for further use.

\subsection{Mechanism of Cd Uptake}

Based on the unique structure of zeolite discussed earlier which is characterized by being both crystalline and porous, the removal of metal ions can be described as ion exchange, sieve action or both depending on the relative ionic sizes and pore diameter. The average pore diameter of the investigated size cuts of zeolite is $1.75 \AA$ (Table 1) which indicates a macroporous structure. According to the IUPAC standard, pores larger than $50 \mathrm{~nm}(0.5 \AA)$ are considered as macropores. The radii of the crystal, $\mathrm{Cd}^{2+}$, and hydrated, $\mathrm{Cd}(\mathrm{OH})^{+}$, ions are 0.97 and $5.0 \AA$ (Pauling, 1970). The following sequence compares ionic sizes to average zeolite pore size:

Ionic radius of $\mathrm{Cd}^{2+}<$ Zeolite average pore size $<$ Ionic radius of $\mathrm{Cd}(\mathrm{OH})^{+}$

This comparison reveals that it is possible for $\mathrm{Cd}^{2+}$ ions, the major cadmium species present at the experimental conditions $(\mathrm{pH}<8.0)$ to diffuse inside the pores of zeolite in addition to their sorption on the external surface. However, the hydrated ion, $\mathrm{Cd}(\mathrm{OH})^{+}$, is too large to penetrate into the pores and thus its removal is restricted to ion exchange at the external surface. This means that two mechanisms of uptake are plausible: (a) ion exchange process which may occur at the external surface or at the active sites inside the large pores which may be represented by the following chemical equation:

$$
\mathrm{Cd}^{2+}{ }_{(a q)}+2 \mathrm{Na}^{+}(\mathrm{Z}) \mathrm{Cd}^{2+}(\mathrm{Z})+2 \mathrm{Na}_{(a q)}^{+}
$$

(b) sieve action followed by physical adsorption on the internal surface of zeolite pores. There are similar observations of these phenomena reported in the literature (Lee and Moon, 2001; Sprynskyy, et al. 2006).

\section{Conclusions}

Jordanian phillipsite tuff is a cost-effective material for the removal of cadmium ions from aqueous solutions. The study has shown that zeolite dose (slurry concentration) and initial cadmium ion concentration are key factors influencing equilibrium uptake.Slurry $\mathrm{pH}$ increased slightly with sorption progress. Equilibrium uptake is best modeled by Langmuir model implying monolayer cover- 
age at specific charged sites. Breakthrough curves obtained demonstrated the applicability of the tested zeolite mineral in continuous fixed bed column operation. The combination of bed height and solution flow rate are the two parameters to adjust for enhanced bed efficiency at a given cadmium ion concentration in the feed. Solution chemistry at $\mathrm{pH}<8.0$ as well as pore diameter of zeolite supports cadmium uptake mechanism by both ions exchange and sieve action.

\section{References}

Al-Haj-Ali, A. and El-Bishtawi, R., 1997, "Removal of Metal Ions Using Jordanian Zeolite Tuff", J. of Chem. Technol. Biotechnol., Vol. 69, pp. 27-34.

Al-Haj-Ali, A. and Al-Hunaidi, T., 2004, "Breakthrough Curves and Column Design Parameters for Sorption of Lead Ions by Natural Zeolite", Environmental Technology, Vol. 25, pp. 1009-1019.

Alloway, B.J., 1995, "Heavy Metals in Soil", Wiley, New York.

Alvarez-Ayuso, E.; Garcia-Sanchez, A. and Querol, X., 2003, "Purification of Metal Electroplating Wastewaters Using Zeolites", Water Research Vol. 37, pp. 4855-4862.

Berber-Mendoza, M.S., Leyva-Ramos, R., AlonsoDavilla, P., Mendoza-Barron, J. and Diaz-Flores, P.E., 2006, "Effect of $\mathrm{pH}$ and Temperature on the IonExchange Isotherm of $\mathrm{Cd}(\mathrm{II})$ and $\mathrm{Pb}(\mathrm{II})$ on Clinoptilolite", J. of Chem. Technol. Biotechnol., Vol. 81, pp. 966-973.

Burgess, J., 1988, "Ions in Solution: Basic Principles of Chemical Interactions", Ellis Horwood, London, UK.

Camilo, C.; Carmen, G. and Paula, M., 2005, "Sorption Characteristics of Heavy Metal Ions by a Natural Zeolite", J. of Chem. Technol. Biotechnol. Vol. 80(4), pp. 477-481

Cincotti, A., Mameli, A., Locci, A. M., Orru, R. and Cao, G., 2006, "Heavy metal Uptake by Sardinian Natural Zeolites: Experiment and Modeling", Industrial \& Eng. Chem. Research Vol. 45, pp. 1074-1084.

Dabrowski, A., Hubicki, Z., Podkoscielny, P. and Robens, E., 2004, "Selective Removal of the Heavy Metal Ions from Waters and Industrial Wastewaters by IonExchange Method", Chemosphere, Vol. 56, pp. 91106.

Dwairi, I. M., 1992, "Evaluation of Jordanian Zeolite Tuffs for Decontamination and Immobilization of Cs", DIRASAT, Vol. 19B, pp. 61-73.

Friberg, L.M., Piscaor, G.F. and Nordberg, T., 1974, "Cadmium in the Environment", Second edition, CRC Press, Cleveland, US.

Garcia-Sanchez, A., Alvarez-Ayuso, E. and Jimenez de Blas, O., 1999, "Sorption of Heavy Metals from Industrial Wastewater by Low-Cost Mineral Silicates", Clay Minerals, Vol. 34, pp. 469-477.

Genc-Fuhrman, H., Mikkelson, P. and Ledin, A., 2007, "Simultaneous Removal of As, Cd, Cr, Cu, Ni and Zn from Stormwater: Experimental Comparison of 11Different Sorbents", Water Research, Vol. 41, pp. 591-602.

Hedstrom, A., 2001, "Ion Exchange of Ammonium in Zeolites: A Literature Review", J. of Environ. Eng., Vol. 127(8), pp. 673-681.

Inglezakis, V.J. and Grigoropoulou, H., 2004,"Effects of Operating Conditions on the Removal of Heavy Metals by Zeolite in Fixed Bed Reactors", J. of Hazardous Materials, Vol. 112(1-2), pp. 37-43.

Kocaoba, S.; Orhan, Y. and Akyuz, T., 2007, "Kinetics and Equilibrium Studies of Heavy Metal Ions Removal by Use of Natural Zeolite", Desalination, Vol. 214, pp. 110.

Lee, D.H. and Moon, H., 2001, "Adsorption Equilibrium of Heavy Metals on Natural Zeolites", Korean J. of Chem. Eng., Vol. 18(2), pp. 247-256.

Ouki, K.S., Cheeseman, C.R. and Perry, R., 1994, "Natural Zeolite Utilization in Pollution Control: A Review of Applications to Metals' Effluents", J. of Chem. Technol. Biotechnol., Vol. 59(2), pp. 121-126.

Pauling, L., 1970,"General Chemistry", W.H. Freeman \& Co., New York.

Rangel-Mendez, J.R. and Streat, M., 2002, "Adsorption of Cadmium by Activated Carbon Cloth: Influence of Surface Oxidation and Solution pH", Water Researech, Vol. 36, pp. 1244-1252.

Rashdan, Z F., 2000, "Investigation of Natural Zeolitic Tuffs on Their Ability for Sewage Cleaning Purposes", PhD. Thesis, Dept. of Chemistry, Oldenburg University, Oldenburg, Germany, pp. 102107.

Sand, L.B. and Mumpton, F.A., 1978, "Natural Zeolites: Occurance, Properties, Use", Pergamon Press, Oxford, UK.

Singh, S.P., Ma, L.Q. and Harris, W.G., 2001," Heavy Metal Interactions with Phosphatic Caly: Sorption and Desorption Behavior", J. of Environmental Quality, Vol. 30, pp. 1968-1975.

Sips, R., 1948, "On the Structure of a Catalyst Surface", J. of Chemical Physics, Vol.16, p.490.

Sprynskyy, M., Buszewski, B., Terzyk, A. and Namiesnik, J., 2006, "Study of the Selection Mechanism of Heavy Metal $\left(\mathrm{Pb}^{2+}, \mathrm{Cu}^{2+}, \mathrm{Ni}^{2+}\right.$ and $\left.\mathrm{Cd}^{2+}\right)$ Adsorption on Clinoptilolite", J. of Colloid \& Interface Sci., Vol. 304, pp. 21-28.

Srivastava, P., Singh, B. and Angrove, M.J., 2004, "Competitive Adsorption of Cadmium (II) onto Kaolinite as Affected by $\mathrm{pH}^{\text {", }} 3^{\text {rd }}$ Australian New Zealand Soils Conference, University of Sydney, Australia, 5-9 December, 2004.

Stumm, W. and Morgan, J.J., 1996, "Aquatic Chemistry: Chemical Equilibria and Rates in Natural Waters", Third edition, Wiley, New York.

Takac, S., Calik, G., Aytar, M. and T. Ozdamar, T., 1998, "Separation Kinetics of 1-Phenyl-Amine by IonExchange Process", Biochem. Eng. J., Vol. 2, pp. 101-112. 
The Journal of Engineering Research Vol. 6, No. 2 (2009) 1-11

Vaca-Mier, M., Callejas, R.L., Gehr, R., Cisneros, E.E.J. and Alvarez, P.J., 2001, "Heavy Metal Removal with Mexican Clinoptilolite: Multi-Component Ionic Exchange", Water Research, Vol. 35(2), pp. 373-378.
WHO (World Health Organization), 2004, "Guidelines for Drinking Water Quality", Third Edition, WHO, Geneva. 